\title{
Medical responsibility in the case of patients referred to non-medical staff of a mental health unit or trust directly from non-medical services
}

\author{
Statement by The Royal College of Psychiatrists
}

A consultant psychiatrist can accept responsibility only for a patient of whom he or she has specific knowledge, thereby having the authority to diagnose illness and prescribe treatment. Such authority may be delegated, but the responsibility cannot be abrogated.

Members of the Royal College of Psychiatrists are aware that non-medical mental health professionals sometimes refer patients with psychiatric and psychological disabilities to other non-medical personnel, without clarifying who is holding medical responsibility for that patient. If non-medical professionals accept referrals from a non-medical source (which can include self-referrals, as well as referrals from an agency, such as the social services) they and their managers should be clear about where medical responsibility is held, and what indemnity they have should legal proceedings arise from their management of the case.

Approved by Council

January 1993

\section{ICD-10 and the MRCPsych Examinations}

I would be grateful if all concerned would note that ICD-10 will be officially adopted in April 1994. Until that date, any specific reference in written papers will be to ICD-9; in clinical and oral examinations, I would expect a gradual transition with examiners familiarising themselves with ICD-10, and candidates being acquainted with ICD-9 or both. I would also draw attention to the note regarding the Classification of Disorders, MRCPsych Examinations Notice, Psychiatric Bulletin, 1991, 15, 377).

Dr Sheila A. MaNN Chief Examiner

\section{Transcultural Psychiatry Special Interest Group}

There will be a meeting of the Special Interest Group on Wednesday, 5 May 1993 at the Royal College of Psychiatrists. The theme of the meeting will be 'Purchasing Care for Minority Ethnic Communities'.
Members will receive details of this meeting shortly.

Non-members of the Special Interest Group requiring further information should contact Jean Wales at the College.

\section{Philosophy Special Interest Group}

The 1994 Residential Conference of the Philosophy Special Interest Group will be held in Newcastle from 17 to 19 February. The theme of the conference will be
'Religion, Psychiatry and Contemporary Experience'. Non-members of the Special Interest Group should contact Jean Wales at the College for further details. 